\title{
Genotoxicity Clues to Predict Intervertebral Disc Degeneration: A Systematic Review
}

\section{Charles André Carazzo ${ }^{*}$, Bruno Saciloto ${ }^{1}$, Manuela Peletti Figueiró ${ }^{2}$, Natalia Fontana Nicoletti², Asdrubal Falavigna ${ }^{1,2}$}

${ }^{1}$ Health Sciences postgraduate Program, University of Caxias do Sul (UCS), Caxias do Sul, Brazil ${ }^{2}$ Cell Therapy Laboratory (LATEC), University of Caxias do Sul (UCS), Caxias do Sul, Brazil

Email: cacarazzo@hotmail.com, brunosaciloto@gmail.com, manu.peletti@gmail.com,nfnicoletti@ucs.br, asdrubalmd@gmail.com

How to cite this paper: Carazzo, C.A. Saciloto, B., Figueiró, M.P., Nicoletti, N.F. and Falavigna, A. (2020) Genotoxicity Clues to Predict Intervertebral Disc Degeneration: A Systematic Review. Journal of Biosciences and Medicines, 8, 68-77.

https://doi.org/10.4236/jbm.2020.812007

Received: November 1, 2020

Accepted: December 12, 2020

Published: December 15, 2020

Copyright $\odot 2020$ by author(s) and Scientific Research Publishing Inc. This work is licensed under the Creative Commons Attribution International License (CC BY 4.0).

http://creativecommons.org/licenses/by/4.0/

\begin{abstract}
Objective: To characterize the association between DNA damage and Intervertebral disc degeneration (IDD). Summary of Background Data: IDD is the main disorder causing low back pain and is the most promising target for intervention. Many factors can contribute to the etiology, such as genetics, environment and lifestyle, but it is not yet fully understood. DNA damage can influence this process and needs to be studied, as well as the agents that can determine these damages. Methods: A systematic literature search of PubMed, Web of Science and Scopus was performed to identify studies related to DNA damage to the intervertebral disc. Results: After screening 61 records, 7 articles were included according to the selection criteria. All studies showed some relation between DNA damage and IDD. However, DNA damage was always considered a secondary issue to be investigated. Conclusions: Many factors can influence DNA damage induced by different genotoxic agents on the degenerative cascade of IVD. However, the correlation between IDD severity and DNA damage, as well as the factual role of DNA damage in disc degeneration could not be defined.
\end{abstract}

\section{Keywords}

DNA Damage, Genotoxicity, Biomarker, Intervertebral Disc Degeneration

\section{Introduction}

Intervertebral disc degeneration (IDD) has been considered the main etiology of low back pain, and it will affect over $80 \%$ of the population worldwide at some point in their lives [1]. IDD generates high disability rates and high treatment 
costs with medication for pain relief, physical therapy, spinal injections, and surgery [1].

Despite the high impact on the patients' lives, the etiology and pathophysiology of IDD are not fully understood [2]. The degenerative disc process begins early in life and has been related to aging and cellular senescence due to change in the extracellular matrix (ECM) and decreasing collagen and proteoglycan production [2]. Genetics, environmental factors, and lifestyle contribute to disc degeneration [3] [4] [5] [6] [7]. Genetic influence on disc degeneration is up to $74 \%$ [3] [8] [9] [10]. Obesity, smoking daily, and mechanical loading are independent conditions related to IDD [11] [12]. A lower influence of repetitive physical loading was observed in a twins study [13]. The correlation between IDD with genetics and environment was observed in the COL9A3 polymorphism and persistent obesity [14] and the whole-body vibration and IL1A-889T allele [15].

DNA damage and alterations of gene expression by extrinsic or intrinsic factors can be an important biomarker of IDD. The objective of this paper is to perform a literature review on the impact of DNA damage on IDD to determine genotoxic biomarkers as well as to indicate the best assay to evaluate DNA damage for IDD.

\section{Methodology}

The review was conducted following the methodological guidelines outlined by the Transparent Reporting of Systematic Reviews and Meta-Analyses (PRISMA) [16].

\subsection{Literature Search Strategy}

PubMed.gov (www.ncbi.nlm.nih.gov/pubmed), Web of Science

(https://webofknowledge.com) and Scopus (www.scopus.com) were searched to identify articles related to DNA damage of the intervertebral disc from January 2000 to August 2018. References derived from the included studies were evaluated to find additional reference articles pertaining to the topic.

The criteria for the search in all fields were the following string: ((DNA damage OR genotoxic OR genotoxicity) AND (Intervertebral Disc OR Nucleus pulposus OR Annulus Fibrosus OR Cartilage Endplate) AND (Intervertebral Disc Disease OR Intervertebral Disc Degeneration)).

The results found in the three databases were compared, duplicate records were removed, and the rest were screened for inclusion by title and abstract review. Full-text article review was performed to ensure that all relevant papers were captured. Eligibility assessment was performed independently in a standardized manner by two reviewers (authors C.A.C. and N.F.N.). Discrepancies between reviewer assessments were discussed with an independent, blinded third reviewer (author A.F.) until a consensus was reached.

\subsection{Eligibility Criteria for Study Selection}

The following were used as selection criteria: articles published in English; studies that included analysis of DNA damage on intervertebral disc; studies that 
analyzed the genotoxicity on intervertebral disc and articles that was published in a peer-reviewed journal. Exclusion criteria consisted of systematic reviews or meta-analyses, letters to the Editor, commentaries, papers that did not involve DNA damage and genotoxicity, or analysis of DNA damage and genotoxicity in other tissues rather than the intervertebral disc.

\subsection{Data Extraction and Analysis}

After the exclusion process, the full text of each article was reviewed. Baseline characteristics of each article were extracted from each paper: Author, year of publication, type of study, experimental model used, evaluation of DNA damage and genotoxicity, and follow up. These outcomes were compiled and organized using Microsoft Excel.

\section{Results}

All studies found in this review were published in the last five years (2013 to 2018), which shows the recent interest concerning the genotoxicity and IDD development and/or outcome. However, in most of them, the DNA damage was considered a secondary issue and not a key regulatory event to solve questions about intervertebral disc damage.

\section{Study Characteristics}

The database search was performed and yielded 61 studies and a flow diagram illustrating the screening process (Figure 1-PRISMA). Among the collected studies, 20 of the articles were removed because they were duplicates. The abstracts of 41 non-duplicate articles were screened and 33 were discarded for not meeting the search criteria ( 6 reviews; 12 studies related to other applications and 15 did not involve the disease or DNA damage).

The remaining 8 full-text articles were included for analysis. After the full-text articles were read, one more article was excluded because it did not analyze the DNA damage, but rather DNA quantification to evaluate cellular proliferation. Finally, 7 studies were included in the present review.

The animal models and techniques used to cause and evaluate the DNA damage were different from one study to another. The majority used rat models to obtain samples for in vitro analysis and only one investigated the genotoxic profile in human disc cells [17]. DNA damage was identified using primary antibodies, against histone $\gamma$-H2A.X in four studies [17] [18] [19] [20], PicoGreen assay in two [21] [22] and comet assay in only one [23]. Heterogeneity was also found in DNA damage-inducing agents. A mechanical agent was studied in three papers [18] [19] [22], chemical agents in five articles [17] [20] [21] [22] [23], and both mechanical and chemical effects in only one paper [22]. Mechanical agents included cyclic mechanical tension (CMT), high oxygen tension and ionizing radiation. The chemical agents employed included $\mathrm{N}$-acetylated proline-glycine-proline (N-Ac-PGP), hydrogen peroxide $\left(\mathrm{H}_{2} \mathrm{O}_{2}\right)$, tobacco smoke and 


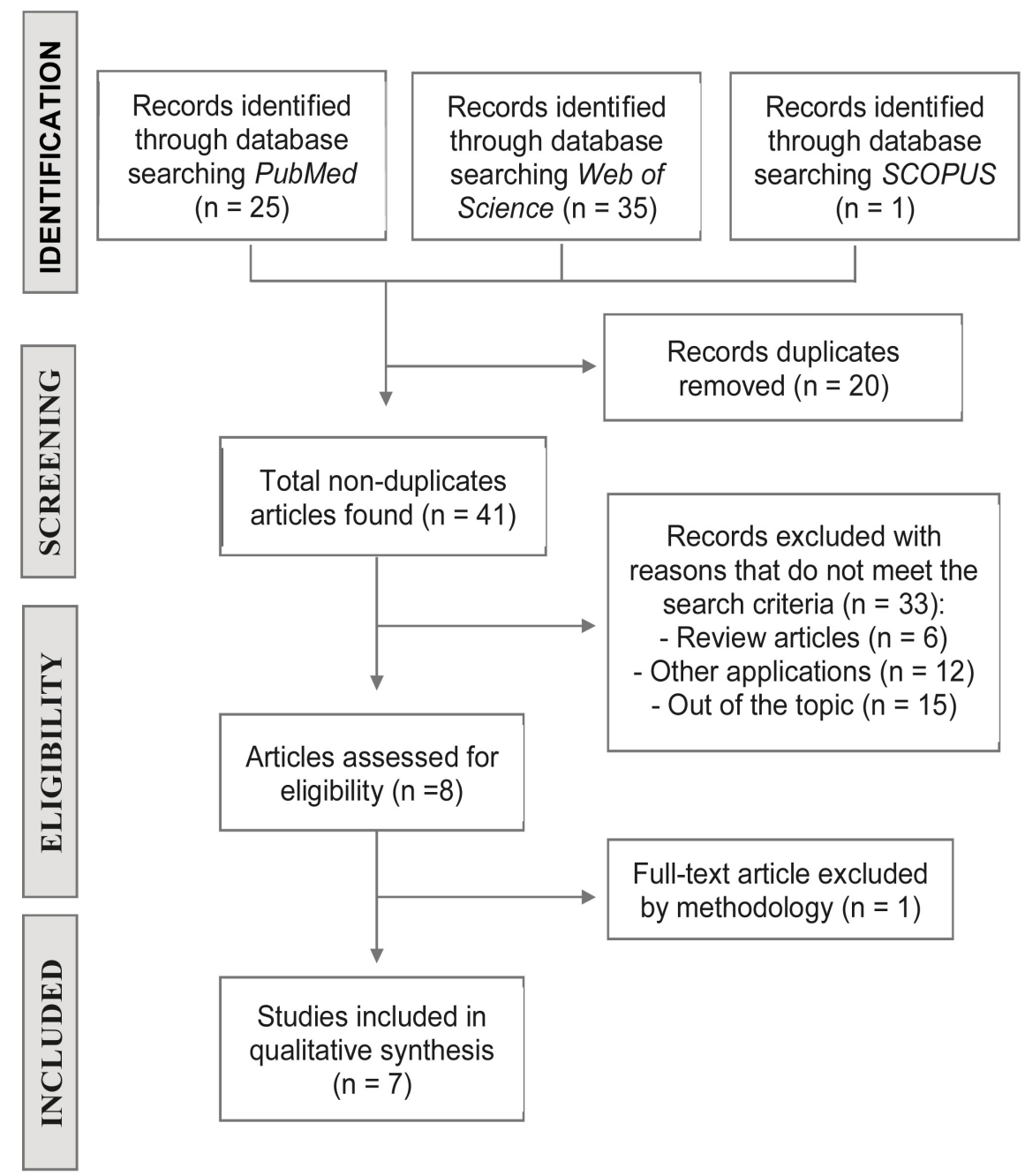

Figure 1. Systematic review flowchart, including inclusion and exclusion criteria.

mechlorethamine (MEC). Studies demonstrated the relationship between mechanical/chemical agents that damage the DNA of Intervertebral disc (IVD) cells and different up- or down-regulated pathways that establish genotoxic influence on IDD pathogenesis (Table 1).

\section{Discussion}

IDD has been extensively studied due to the chronic condition and its high incidence, which leads to high-cost treatments and interventions that often do not provide a resolution [24]. Extrinsic factors contributed to disc degeneration changes such as cigarettes and obesity [11] [12]. Intrinsic factors and genetic profile also play an important role in IDD and influenced the mechanisms of cell senescence [3] [8]. Despite all the investigative efforts, the real influence of the DNA damage on the degenerative cascade, the intrinsic and extrinsic factors involved and the best biomarkers to guide the disc degeneration prognosis are not fully understood. There is still a vast field of study to understand the impact of DNA damage on IDD development and prognosis. 
Table 1. Characteristics of included studies.

\begin{tabular}{|c|c|c|c|c|c|c|}
\hline Author/Year & $\begin{array}{c}\text { Type of } \\
\text { DNA damage }\end{array}$ & Model & $\begin{array}{l}\text { Donor tissue/ } \\
\text { Cell types }\end{array}$ & $\begin{array}{c}\text { DNA } \\
\text { Damage Assay }\end{array}$ & $\begin{array}{l}\text { DNA } \\
\text { damage }\end{array}$ & $\begin{array}{l}\text { Main pathway } \\
\text { related to DNA damage }\end{array}$ \\
\hline \multicolumn{7}{|c|}{ Mechanical } \\
\hline Feng, 2018 [18] & $\begin{array}{l}\text { Cyclic mechanical tension } \\
\text { (CMT) }\end{array}$ & in vitro & Rat NP cells & $\begin{array}{l}\text { BrdU Incorporation } \\
\text { and } \gamma \text {-H2A.X }\end{array}$ & Positive & $\begin{array}{l}\text { p53-p21-retinoblastoma } \\
\text { protein }(\mathrm{Rb})\end{array}$ \\
\hline Feng, 2017 [19] & $\begin{array}{l}\text { High oxygen tension } \\
\left(20 \% \mathrm{O}_{2}\right)\end{array}$ & in vitro & Rat NP cells & $\begin{array}{l}\text { BrdU Incorporation } \\
\text { and } \gamma \text {-H2A.X }\end{array}$ & Positive & $\begin{array}{l}\text { p53-p21-retinoblastoma } \\
\text { protein }(\mathrm{Rb}) \\
\text { P16-retinoblastoma } \\
\text { protein }(\mathrm{Rb})\end{array}$ \\
\hline Nasto, 2013 [22] & Ionization Radiation (IR) & In vitro & $\begin{array}{l}\text { Rat } \mathrm{NP} \text { and } \mathrm{AF} \\
\text { cells }\end{array}$ & PicoGreen assay & Positive & $\begin{array}{l}\text { ROS production } \\
\text { Direct physical effect }\end{array}$ \\
\hline \multicolumn{7}{|c|}{ Chemical } \\
\hline Feng, 2017 [20] & $\begin{array}{l}\mathrm{N} \text {-acetylated proline-glycine- } \\
\text { proline }(\mathrm{N}-\mathrm{Ac}-\mathrm{PGP})\end{array}$ & In vitro & Rat NP cells & $\begin{array}{l}\text { BrdU Incorporation } \\
\text { and } \gamma \text {-H2A.X }\end{array}$ & Positive & $\mathrm{p} 53-\mathrm{p} 21-\mathrm{Rb}$ and $\mathrm{p} 16-\mathrm{Rb}$ \\
\hline $\begin{array}{l}\text { Dimozi, } 2015 \\
\text { [17] }\end{array}$ & Hydrogen peroxide $\left(\mathrm{H}_{2} \mathrm{O}_{2}\right)$ & In vitro & $\begin{array}{l}\text { Human NP } \\
\text { cells }\end{array}$ & $\begin{array}{l}\text { BrdU Incorporation } \\
\gamma \text {-H2A.X }\end{array}$ & Positive & $\mathrm{p} 53-\mathrm{p} 21-\mathrm{Rb}$ \\
\hline Nasto, 2014 [21] & Tobacco smoke & In vitro & Rat NP cells & PicoGreen assay & Positive & Direct effect \\
\hline Nasto, 2013 [22] & Mechlorethamine (MEC) & In vitro & $\begin{array}{l}\text { Rat NP and AF } \\
\text { cells }\end{array}$ & PicoGreen assay & Positive & $\begin{array}{l}\text { Lack of ERCC1 } \\
\text { endonuclease }\end{array}$ \\
\hline Zhou, 2013 [23] & Hydrogen peroxide $\left(\mathrm{H}_{2} \mathrm{O}_{2}\right)$ & In vitro & Rat NP cells & Comet assay & Positive & INK4A-ARF pathway \\
\hline
\end{tabular}

NP: nucleus pulposus; ROS: reactive oxygen species; BrdU: Bromodeoxyuridine.

\subsection{Genetic Influences}

Studies on identical twins showed $74 \%$ to $77 \%$ heritability rates of IDD, highlighting the importance of the genetic component in the pathophysiology of the degenerative processes [3] [25]. A high number of candidate genes and mutated alleles are responsible for the morphology and function of ECM and are related to the heritage of IDD pathophysiology [26] [27]. The most common genetic variations are the polymorphisms found in genes that affect collagens I, II, III, IX, XI, and aggrecan synthesis; the release of interleukins I, VI, X, and matrix metalloproteinases enzymes II, III, IX, and vitamin D receptor [25] [26]. It is impossible to precise if the alteration of IDD came from genetic or aging process.

\subsection{Disc Aging and Senescence}

The IDD has morphological and functional changes related to the aging progress [28]. Different IVD structures at different times are affected during its natural process, which could become a source of pain and disability leading to the pathological condition that characterizes the IDD. Unfortunately, it is not yet possible to predict in advance which IVD will become symptomatic since there is a lack of specific biomarkers to distinguish it. 
Cellular senescence consists of an irreversible cellular aging process that arrests the cell cycle of the telomere shortening [2] [29]. The main hypothesis accepted for disc senescence is based on the imbalance between anabolic and catabolic mechanisms that accelerated degeneration by degrading the ECM of the disc [29] [30]. The increases of matrix degradation enzymes and proinflammatory cytokines promote the degenerative process, with the catabolism outweighing the anabolism [29] (Figure 2). The progressive reduction of telomeres triggered by a DNA damage response leads to incomplete DNA replication and activates the $\mathrm{p} 53-\mathrm{p} 21-\mathrm{Rb}$ signaling pathway, that promotes the replicative senescence. These reductions of proteoglycan production and collagen release create an oxidative stress environment, which increases the reactive oxygen metabolites that inhibit disc cell proliferation and activate the p16-Rb signaling pathway to induce a cell cycle arrest of disc cells in response to DNA damage [2] [29].

\subsection{Genotoxic Clues}

Feng and coworkers [18] studied the senescent response of disc cells to mechanical stress. This experimental work demonstrated that the unphysiological cyclic mechanical tension increased premature cell senescence due to a direct genotoxic effect on DNA damage in NP rat cells by the formation of $\gamma$-H2A.X foci in the nuclei of NP cells. Premature senescence of NP cells started $48 \mathrm{~h}$ post-stimulation and occurred in a time-dependent manner for up to 12 hours of cyclic mechanical tension application, suggesting that the longer the application time of an unphysiological load on the disc, the greater will be the DNA damage and senescent cell formation on it will be [18]. In another paper by the same research group, the authors evaluated the influence of high oxygen tension

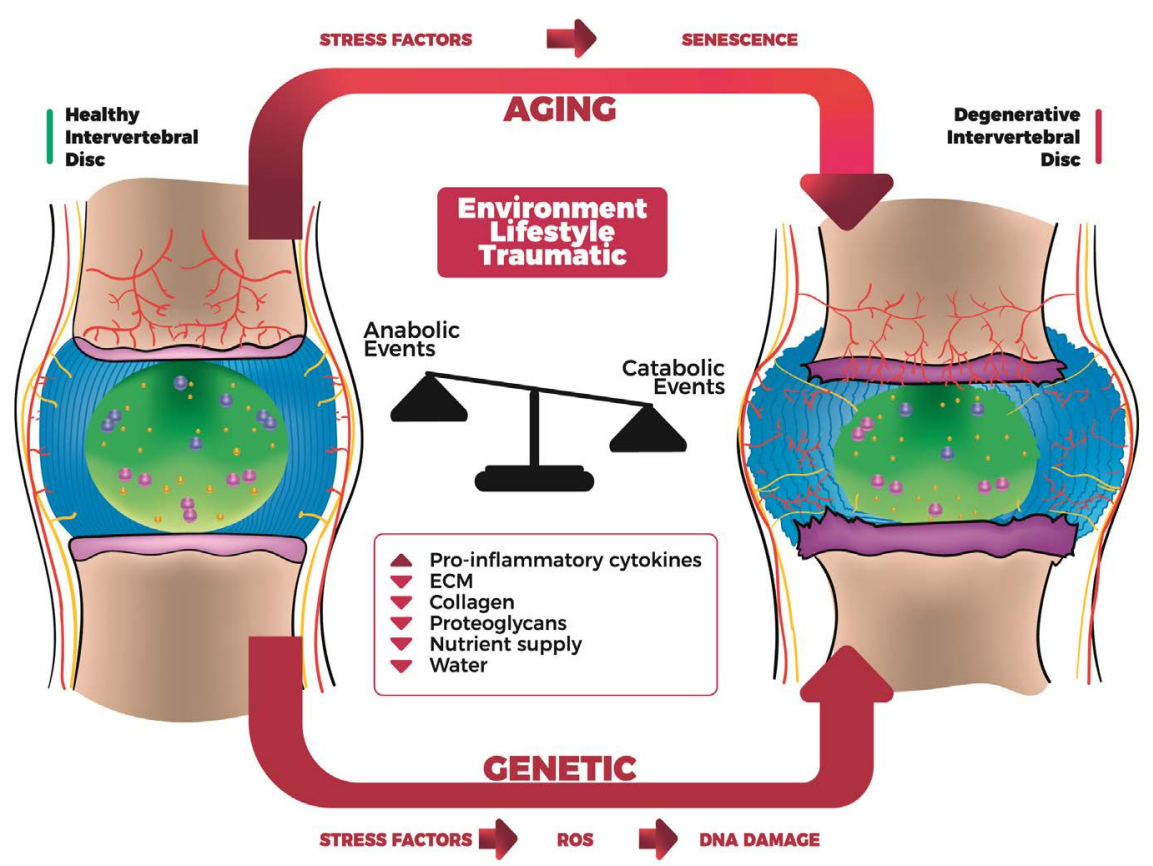

Figure 2. Schematic drawing of the main etiologic factors involved disc degeneration. 
$\left(\mathrm{O}_{2} 20 \%\right)$ on disc cell senescence and proved that the enhancement of Reactive Oxygen Species (ROS) leads to DNA damage by upregulation of p53-p21-Rb and p16-Rb pathways to mediate premature pro-senescent effect [19].

Another intrinsic agent involved in this process is the $\mathrm{N}$-acetylated proline-glycine-proline (N-Ac-PGP), a chemokine derived from collagen that was recently found in the degenerative human NP and reinforces the inflammatory contribution to the evolution of senescence [31]. The relation between $\mathrm{N}$-Ac-PGP and disc cell senescence was evaluated in an in vitro culture of rat NP cells and showed an enhancement of ECM catabolism followed by inflammatory cascades and consequent premature senescence induced by N-Ac-PGP [20]. In addition, the elevated percentage of $\mathrm{y}$-H2A.X-positive cells also suggested DNA damage linked to ROS production and upregulation of both $\mathrm{p} 53-\mathrm{p} 21-\mathrm{Rb}$ and p16-Rb pathways, without affecting telomerase activity [20].

Nasto et al. [21] performed a rat in vivo model to evaluate the exposition to an extrinsic agent of tobacco for 7 weeks ( $\sim 3.5$ years in humans). The rats submitted to tobacco inhalation presented significant degenerative changes and loss of proteoglycan matrix components in the IVD. However, these findings can be explained only in part through DNA damage because the effect was mild and not significant $(\mathrm{p}<0.18)$. The lack of disc nutrition and vascularization common in spine degeneration needs to be further studied to prove the role of tobacco smoking-induced DNA damage [21]. DNA damage in mice disc cells was also identified in chronic exposure to the cancer therapeutic agent mechlorethamine and ionizing radiation [22]. These results demonstrated that DNA damage drives the loss of disc homeostasis and plays a major role in this process, starting a degenerative cascade [21] [22].

Zhou et al. [23] and Dimozi et al. [17] evaluated the hydrogen peroxide $\left(\mathrm{H}_{2} \mathrm{O}_{2}\right)$ capability to simulate oxidative stress and induce DNA damage. The expression of chromobox homolog 8 (CBX8), an important protein that plays a role in cellular senescence and DNA repair, was correlated with increased DNA damage in rat NP cells and associated with lost type II collagen and proteoglycans amounts and cell growth inhibition [23]. Interestingly, this was the only study that evaluated DNA damage by comet assay to verify DNA damage in NP cells [23]. Along the same lines, the genotoxicity caused by prolonged exposure to $\mathrm{H}_{2} \mathrm{O}_{2}$ at sub-cytotoxic concentrations induced a catabolic phenotype and led to premature senescence in human intervertebral disc cells [17]. Finally, the high phosphorylation of $\mathrm{y}-\mathrm{H} 2 \mathrm{~A} . \mathrm{X}$ and the upregulation of extracellular matrix-degrading enzymes proved the enhancement of DNA damage [17].

\subsection{Study Limitations}

The limitations of this study come from the paucity of publications on DNA damage related to IDD. All studies were experimental in vitro cultured cells, the main source of cells was the rat NP, the methodology was very heterogeneous and different types of assay were used to establish the DNA damage, and the 
DNA damage was considered a secondary issue to be investigated and not a direct event that could trigger the degeneration process. Those factors explain the difficulties to correlate the intrinsic and extrinsic factors of DNA damage in disc degeneration.

It is critical to pursue further knowledge in this field of DNA damage in the IDD in human disc cells to establish the best assay and methodology. It would be useful pursuit a novel biomarker of prognosis and maximize new treatments for this pathology.

\section{Conclusion}

In conclusion, intrinsic and extrinsic factors directly influence DNA damage induced by different genotoxic agents in the degenerative cascade of IVD. The factual role of DNA damage in disc degeneration needs to be further studied.

\section{Acknowledgements}

The authors acknowledge financial support from the AOSpine Latin America through Master's scholarship to Charles André Carazzo and Bruno Saciloto.

\section{Conflicts of Interest}

The authors have declared no conflicting interest.

\section{References}

[1] Mayer, J.E., Iatridis, J.C., Chan, D., Qureshi, S.A., Gottesman, O. and Hecht, A.C. (2013) Genetic Polymorphisms Associated with Intervertebral Disc Degeneration. The Spine Journal, 13, 299-317. https://doi.org/10.1016/j.spinee.2013.01.041

[2] Roberts, S., Evans, E.H., Kletsas, D., Jaffray, D.C. and Eisenstein, S.M. (2006) Senescence in Human Intervertebral Discs. European Spine Journal, 15, 312-316. https://doi.org/10.1007/s00586-006-0126-8

[3] Sambrook, P.N., MacGregor, A.J. and Spector, T.D. (1999) Genetic Influences on Cervical and Lumbar Disc Degeneration: A Magnetic Resonance Imaging Study in Twins. Arthritis \& Rheumatism, 42, 366-372. https://doi.org/10.1002/1529-0131(199902)42:2<366::AID-ANR20>3.0.CO;2-6

[4] Battie, M.C., Videman, T. and Parent, E. (2004) Lumbar Disc Degeneration: Epidemiology and Genetic Influences. Spine (Phila Pa 1976), 29, 2679-2690. https://doi.org/10.1097/01.brs.0000146457.83240.eb

[5] Ala-Kokko, L. (2002) Genetic Risk Factors for Lumbar Disc Disease. Annals of Medicine, 34, 42-47. https://doi.org/10.1080/078538902317338634

[6] Ashley, J.W., Enomoto-Iwamoto, M., Smith, L.J., et al. (2016) Intervertebral Disc Development and Disease-Related Genetic Polymorphisms. Genes and Diseases, 3, 171-177. https://doi.org/10.1016/j.gendis.2016.04.006

[7] Battié, M.C., Lazáry, Á., Fairbank, J., et al. (2014) Disc Degeneration-Related Clinical Phenotypes. European Spine Journal, 23, 305-314. https://doi.org/10.1007/s00586-013-2903-5

[8] Battie, M.C., Videman, T., Gibbons, L.E., Fisher, L.D., Manninen, H. and Gill, K. (1995) 1995 Volvo Award in Clinical Sciences. Determinants of Lumbar Disc De- 
generation. A Study Relating Lifetime Exposures and Magnetic Resonance Imaging Findings in Identical Twins. Spine (Phila Pa 1976), 20, 2601-2612. https://doi.org/10.1097/00007632-199512150-00001

[9] Battie, M.C. and Videman, T. (2006) Lumbar Disc Degeneration: Epidemiology and Genetics. The Journal of Bone and Joint Surgery, 88, 3-9. https://doi.org/10.2106/00004623-200604002-00002

[10] Battie, M.C., Videman, T., Kaprio, J., et al. (2009) The Twin Spine Study: Contributions to a Changing View of Disc Degeneration. The Spine Journal, 9, 47-59. https://doi.org/10.1016/j.spinee.2008.11.011

[11] Liuke, M., Solovieva, S., Lamminen, A., Luoma, K., Leino-Arjas, P., Luukkonen, R. and Riihimäki, H. (2005) Disc Degeneration of the Lumbar Spine in Relation to Overweight. International Journal of Obesity (Lond), 29, 903-908. https://doi.org/10.1038/sj.ijo.0802974

[12] Battie, M.C., et al. (1991) 1991 Volvo Award in Clinical Sciences. Smoking and lumbar Intervertebral Disc Degeneration: An MRI Study of Identical Twins. Spine (Phila Pa 1976), 16, 1015-1021. https://doi.org/10.1097/00007632-199109000-00001

[13] Videman, T., et al. (1995) The Long-Term Effects of Physical Loading and Exercise Lifestyles on Back-Related Symptoms, Disability, and Spinal Pathology among Men. Spine (Phila Pa 1976), 20, 699-709. https://doi.org/10.1097/00007632-199503150-00011

[14] Solovieva, S., et al. (2002) COL9A3 Gene Polymorphism and Obesity in Intervertebral Disc Degeneration of the Lumbar Spine: Evidence of Gene-Environment Interaction. Spine, 27, 2691-2696. https://doi.org/10.1097/00007632-200212010-00008

[15] Virtanen, I.M., Karppinen, J., Taimela, S., et al. (2007) Occupational and Genetic Risk Factors Associated with Intervertebral Disc Disease. Spine (Phila Pa 1976), 32, 1129-1134. https://doi.org/10.1097/01.brs.0000261473.03274.5c

[16] Moher, D., Shamseer, L., Clarke, M., et al. (2015) Preferred Reporting Items for Systematic Review and Meta-Analysis Protocols (PRISMA-P) 2015 Statement. Systematic Reviews, 4, Article No. 1. https://doi.org/10.1186/2046-4053-4-1

[17] Dimozi, A., Mavrogonatou, E., Sklirou, A. and Kletsas, D. (2015) Oxidative Stress Inhibits the Proliferation, Induces Premature Senescence and Promotes a Catabolic Phenotype in Human Nucleus Pulposus Intervertebral Disc Cells. European Cells \& Materials, 30, 89-103. https://doi.org/10.22203/eCM.v030a07

[18] Feng, C., Yang, M., Zhang, Y., et al. (2018) Cyclic Mechanical Tension Reinforces DNA Damage and Activates the p53-p21-Rb Pathway to Induce Premature Senescence of Nucleus Pulposus Cells. International Journal of Molecular Medicine, 41, 3316-3326. https://doi.org/10.3892/ijmm.2018.3522

[19] Feng, C., Zhang, Y., Yang, M., et al. (2017) Oxygen-Sensing Nox4 Generates Genotoxic ROS to Induce Premature Senescence of Nucleus Pulposus Cells through MAPK and NF- $\kappa$ B Pathways. Oxidative Medicine and Cellular Longevity, 2017, Article ID: 7426458. https://doi.org/10.1155/2017/7426458

[20] Feng, C., Zhang, Y., Yang, M., et al. (2017) The Matrikine N-Acetylated Proline-Glycine-Proline Induces Premature Senescence of Nucleus Pulposus Cells via CXCR1-Dependent ROS Accumulation and DNA Damage and Reinforces the Destructive Effect of These Cells on Homeostasis of Intervertebral Discs. Biochimica et Biophysica Acta-Molecular Basis of Disease, 1863, 220-230. https://doi.org/10.1016/j.bbadis.2016.10.011

[21] Nasto, L.A., et al. (2014) Investigating the Role of DNA Damage in Tobacco Smoking-Induced Spine Degeneration. Spine Journal, 14, 416-423. 
https://doi.org/10.1016/j.spinee.2013.08.034

[22] Nasto, L.A., et al. (2013) Genotoxic Stress Accelerates Age-Associated Degenerative Changes in Intervertebral Discs. Mechanisms of Ageing and Development, 134, 35-42.

[23] Zhou, X., Zhang, H.L., Gu, G.F., et al. (2013) Investigation of the Relationship between Chromobox Homolog 8 and Nucleus Pulposus Cells Degeneration in Rat Intervertebral Disc. In Vitro Cellular \& Developmental Biology-Animal, 49, 279-286. https://doi.org/10.1007/s11626-013-9596-2

[24] Fernandez-Moure, J., Moore, C.A., Kim, K., et al. (2018) Novel Therapeutic Strategies for Degenerative Disc Disease: Review of Cell Biology and Intervertebral Disc Cell Therapy. SAGE Open Medicine, 6, 2050312118761674.

https://doi.org/10.1177/2050312118761674

[25] Kao, P.Y., Chan, D., Samartzis, D., Sham, P.C. and Song, Y.Q. (2011) Genetics of Lumbar Disk Degeneration: Technology, Study Designs, and Risk Factors. Orthopedic Clinics of North America, 42, 479-486.

https://doi.org/10.1016/j.ocl.2011.07.011

[26] Hanaei, S., Abdollahzade, S., Khoshnevisan, A., Kepler, C.K. and Rezaei, N. (2015) Genetic Aspects of Intervertebral Disc Degeneration. Reviews in the Neurosciences, 26, 581-606. https://doi.org/10.1515/revneuro-2014-0077

[27] Rigal, J., Leglise, A., Barnetche, T., Cognietm A., Aunoble, S. and Le Huec, J.C. (2017) Meta-Analysis of the Effects of Genetic Polymorphisms on Intervertebral Disc Degeneration. European Spine Journal, 26, 2045-2052.

https://doi.org/10.1007/s00586-017-5146-Z

[28] Colombier, P., Clouet, J., Hamel, O., Lescaudron, L. and Guicheux, J. (2014) The Lumbar Intervertebral Disc: From Embryonic Development to Degeneration. Joint Bone Spine, 81, 125-129. https://doi.org/10.1016/j.jbspin.2013.07.012

[29] Feng, C., Liu, H., Yang, M., Zhang, Y., Huang, B. and Zhou, Y. (2016) Disc Cell Senescence in Intervertebral Disc Degeneration: Causes and Molecular Pathways. Cell Cycle, 15, 1674-1684. https://doi.org/10.1080/15384101.2016.1152433

[30] Dowdell, J., Erwin, M., Choma, T., Vaccaro, A., Iatridis, J. and Cho, S.K. (2017) Intervertebral Disk Degeneration and Repair. Neurosurgery, 80, S46-s54. https://doi.org/10.1093/neuros/nyw078

[31] Feng, C., Zhang, Y., Yang, M., Huang, B. and Zhou, Y. (2015) Collagen-Derived N-Acetylated Proline-Glycine-Proline in Intervertebral Discs Modulates CXCR1/2 Expression and Activation in Cartilage Endplate Stem Cells to Induce Migration and Differentiation toward a Pro-Inflammatory Phenotype. Stem Cells, 33, 3558-3568. https://doi.org/10.1002/stem.2200 